\title{
Surgical treatment of stage IV gastric cancer: is it worthwhile?
}

\author{
Ilaria Pergolini' ${ }^{1,2}$, Paolo Ciano ${ }^{1,3}$, Gianluca Guercioni', Marco Catarci ${ }^{1}$ \\ 'Department of Surgery, Ospedale "C. e G. Mazzoni", AV5-ASUR Marche, Ascoli Piceno 63100, Italy. \\ 2Department of Surgery, Universita' Politecnica delle Marche, Ancona 60030, Italy. \\ ${ }^{3}$ Department of Surgery, Università Tor Vergata, Rome 00133, Italy.
}

Correspondence to: Dr. Marco Catarci, Department of Surgery, Ospedale "C. e G. Mazzoni", AV5-ASUR Marche, Ascoli Piceno 63100, Italy. E-mail: marcocatarci@gmail.com

How to cite this article: Pergolini I, Ciano P, Guercioni G, Catarci M. Surgical treatment of stage IV gastric cancer: is it worthwhile? J Cancer Metastasis Treat 2018;4:33. http://dx.doi.org/10.20517/2394-4722.2017.84

Received: 29 Dec 2017 First Decision: 18 Jan 2018 Revised: 7 Feb 2018 Accepted: 20 Feb 2018 Published: 17 Jul 2018

Science Editor: Masayuki Watanabe Copy Editor: Jun-Yao Li Production Editor: Cai-Hong Wang

\begin{abstract}
Aim: To analyze clinical features and survival outcomes of patients with surgically-treated stage IV gastric cancer, in order to evaluate the suitability of surgery in these patients.
\end{abstract}

Methods: We performed a systematic literature search using PubMed, MEDLINE, and Embase on October 9th, 2017. Survival outcomes data were collected.

Results: The original search returned 2434 papers. Thirty-nine studies were included in the final review, of which 26 evaluated liver metastasis resection, four pulmonary metastasis resections and nine palliative gastrectomies. In total 933 patients underwent hepatectomy for liver metastasis from gastric cancer and median survival rates were $73 \%, 37 \%$ and $27 \%$ at 1-, 3- and 5-year respectively, with a median overall survival of 22 months (9-52 months). Data regarding resection of lung metastases were scarce and extremely heterogeneous. In total 1115 patients underwent palliative gastrectomy and median overall survival of patients was 12 months (8-53 months). In the only randomized controlled trial, no survival benefit of additional gastrectomy over chemotherapy alone was found, in contrast with the retrospective studies.

Conclusion: Survival benefit of surgery in advanced gastric cancer is still unclear. Surgery may play an important role in highly selected patients. However, further randomized controlled trials are necessary to clarify the actual impact of surgery in these patients.

Keywords: Gastric cancer, metastasis, surgical treatment

\footnotetext{
@()

(C) The Author(s) 2018. Open Access This article is licensed under a Creative Commons Attribution 4.0 International License (https://creativecommons.org/licenses/by/4.0/), which permits unrestricted use, sharing, adaptation, distribution and reproduction in any medium or format, for any purpose, even commercially, as long as you give appropriate credit to the original author(s) and the source, provide a link to the Creative Commons license, and indicate if changes were made.
}

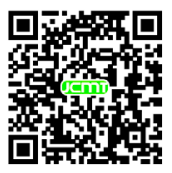




\section{INTRODUCTION}

Gastric carcinoma is the second leading cause of cancer-related death worldwide ${ }^{[1]}$. The 5-year survival for patients with gastric cancer is $30.6 \%$. This decreases to $5.2 \%$ in patients with distant metastases, who comprise $35 \%$ of total patients with a diagnosis of gastric cancer ${ }^{[2,3]}$. Liver metastases occur in $4 \%-14 \%$ of cases, while around $15 \%$ of patients develop pulmonary metastases ${ }^{[4,5]}$. Approximately $70 \%$ of patients are considered ineligible for surgical treatment with curative intent at the time of presentation, due to the presence of locally advanced disease or distant metastases ${ }^{[2]}$. In addition, recurrence occurs in 30\%-50\% of cases, even after curative Ro resection, mainly in the first two years after gastrectomy ${ }^{[6,7]}$.

In this setting, neoadjuvant chemotherapy offers new perspectives in controlling systemic disease and downstaging locally advanced gastric cancer prior to surgery ${ }^{[8]}$. Moreover, several studies have reported promising outcomes of surgical resection in patients with advanced gastric cancer with hepatic or pulmonary metastases. However, the current guidelines are not consistent regarding the most appropriate treatment strategy. The Japanese Gastric Cancer Association (JGCA) and the National Comprehensive Cancer Network $(\mathrm{NCCN})$ guidelines ${ }^{[9,10]}$ do not recommend surgery with curative intent in these patients, leading most patients with metastatic gastric cancer to receive palliative treatment. By contrast, the Guidelines Committee of the JGCA recently reconsidered the treatment of potentially resectable M1 disease in highly selected patients ${ }^{[9,11]}$. The definition of "stage IV" gastric cancer has varied greatly over the last few years; the 7th and 8th versions ${ }^{[12,13]}$ of the American Joint Committee on Cancer (AJCC)/Union for International Cancer Control (UICC) 2010 tumor-node-metastasis (TNM) staging system clearly defined stage IV as any lesion with hematogenous metastases (M1), while previous versions ${ }^{[14]}$ have also included "locally advanced" cases, such as lesions with massive (>15) lymph node metastases (N3) or with direct invasion of adjacent structures (T4). The Japanese Classification of Gastric Cancer did not classify pancreatic head (station 13 and 17) and para-aortic (station 16) lymph node metastases as "distant" (M1) up until the 3rd English Edition in $2011^{[15]}$, whereas western staging systems had accepted this concept long before ${ }^{[14]}$. Which patients with stage IV gastric cancer (either locally advanced or with M1) should be offered a surgical resection and the exact survival benefit of this remain unclear.

This study sought to systematically review the literature in order to evaluate the outcomes of surgical treatment for stage IV gastric cancer and to provide an update on the surgical treatment strategies for this condition.

\section{METHODS}

A systematic literature search was carried out on October 9th, 2017. All references from 2002 to 2017 were potentially eligible for inclusion in the study. The following search strategy was used in PubMed, MEDLINE and Embase: ((((C(((“"gastric cancer”) OR "gastric carcinoma”) OR "gastric neoplasm”) OR “stomach cancer”) OR "stomach carcinoma”) OR "stomach neoplasm”)) AND ((“metastatic”) OR metastas*)) AND (((“liver”) OR "hepatic") OR "lung”) OR "pulmonary”)) AND ((((("surgery”) OR "resection”) OR "palliative surgery”) OR "palliative gastrectomy") OR "surgical")).

A title search was conducted with title review of all identified references. Studies deemed unrelated to study aims were excluded. Abstracts for the remaining studies were retrieved and screened for relevance. Full papers were retrieved for all abstracts deemed potentially eligible. Full papers underwent authors' review and assessment of inclusion/exclusion criteria. Any disagreement during the search and selection process was resolved by consensus.

\section{Inclusion criteria}

- Papers presenting data regarding liver and pulmonary metastasis resection in patients with gastric cancer, without evidence of peritoneal metastases or metastases to other organs. 


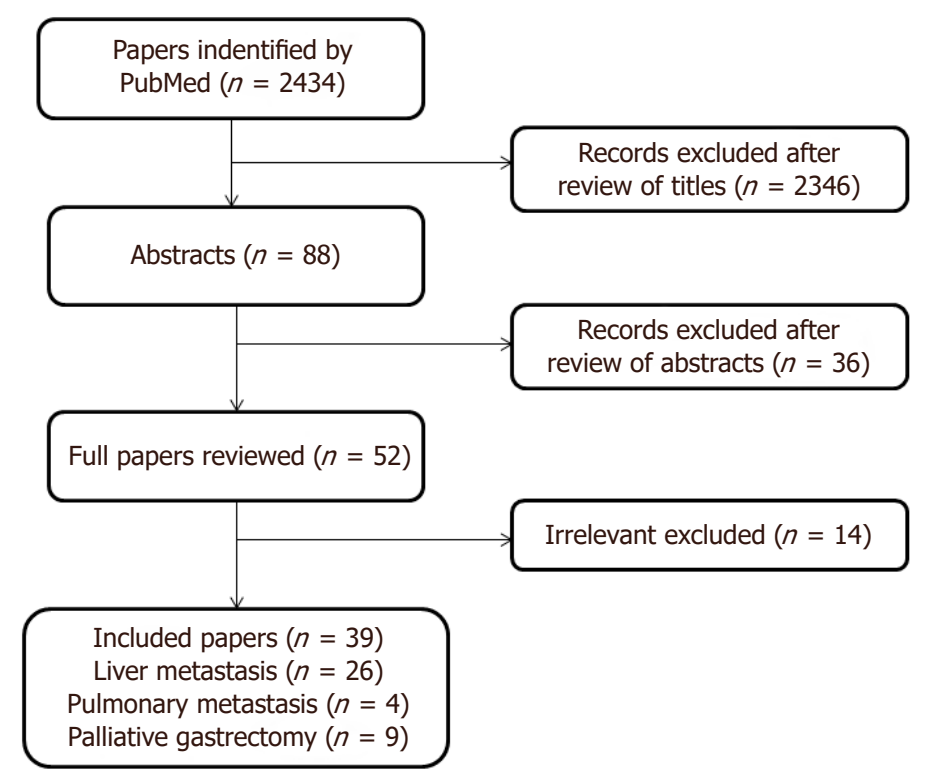

Figure 1. Diagram showing literature selection strategy

- Papers presenting data on patients undergoing palliative gastrectomy, defined as gastric resection without radical intent (microscopic or macroscopic residual disease) in patients with locally advanced disease or in patients with distant metastases.

- Original data (no review papers).

- Survival outcomes data available for at least 1 year following surgical resection. Papers relating to hepatic metastases must have reported at least the median survival time.

- Patient recruitment after 1980.

\section{Exclusion criteria}

- Non-English language studies.

- Full manuscript not available (e.g., abstracts presented at conferences).

- Studies with less than ten patients.

- Malignancy other than epithelial carcinoma ${ }^{[16,17]}$.

The following data were collected: author details, country, recruitment period, study design, median followup, sample size, gender, positive and negative findings, and methodological quality. The primary outcome assessed was survival following surgical resection.

Considering the extreme heterogeneity of inclusion criteria of each paper, we aimed to review the literature descriptively without an intent of inference.

\section{RESULTS}

The original search returned 2434 papers. Figure 1 shows the study search strategy. Overall, 39 studies were included in the final review (26 for hepatic resection ${ }^{[18-43]}, 4$ for pulmonary resection ${ }^{[4-47]}$ and 9 for palliative gastrectomy ${ }^{[48-55]}$.

\section{Liver metastasis surgical treatment}

The 26 studies included provided data on 933 patients who underwent gastrectomy and synchronous or metachronous hepatectomy. The median sample size was 24 patients (range 11-256). Baseline characteristics 
are described in Table 1 and Supplementary Table 1. The median age of patients undergoing hepatectomy was 64 years (range $57-72$ years) and 78\% of patients were males. There was a wide variety of disease burden in patients undergoing hepatectomy. Hepatic lesions were solitary and unilobar in $65 \%$ and $78 \%$ respectively. Fifty five percent of patients developed synchronous metastases, while $45 \%$ developed metachronous lesions. The majority of hepatectomies were minor resections for limited disease, although $42 \%$ of patients underwent major resections.

Details on chemotherapy used were also reported in 19 studies, including data on 775 patients. Of these, $15 \%$ received neoadjuvant chemotherapy and $46 \%$ received adjuvant chemotherapy. A wide variety of chemotherapy regimens were described, while seven studies did not state what chemotherapeutic agents their patients received ${ }^{[18,23,24,29,34,39,41]}$.

Survival outcomes are summarized in Table 2. Median follow-up was 24 months (range 9-65 months). Twenty-one studies presented 1-year survival rates ranging from $36 \%$ to $96 \%, 19$ presented 3-year survival rates ranging from $14 \%$ to $70 \%$ and 25 studies presented 5 -year survival rates of between $9 \%$ to $42 \%$. Median survival rates were $73 \%, 37 \%$ and $27 \%$ at 1-, 3- and 5-year respectively. Median overall survival was 22 months (range 9-52 months).

Seven of the 26 studies compared survival outcomes between resected patients and those who underwent chemotherapy alone. Surgery demonstrated a survival advantage in all of them.

\section{Pulmonary metastasis surgical treatment}

Eighty-three patients provided by four studies underwent resection of pulmonary metastases from gastric cancers. Resection of gastric cancer lung metastases has rarely been reported and few data are available regarding short- and long-term outcomes of this procedure. The majority of patients with pulmonary metastases from gastric cancer present with carcinomatous lymphangitis or pleuritis, whereas nodular lesions are less common ${ }^{[56]}$.

Baseline characteristics are described in Table 3 and Supplementary Table 2. Median age was 66 years (range 56-68 years), and males represented the majority of resected patients ( $83 \%$ vs. $17 \%)$. All patients underwent gastrectomy and subsequent pulmonary metastasectomy. Hundred percent of included patients displayed metachronous metastases and $73 \%$ of these were solitary lesions. Overall $39 \%$ of patients underwent lobectomy, while wedge resection or segmentectomy was performed in $61 \%$. In 3 studies ${ }^{[45-47]}$, indications for performing surgery were decided based on Thomford's criteria ${ }^{[57]}$. Shiono et al.$^{[44]}$ did not specify the criteria for surgical resection. Details on chemotherapy were reported in 3 studies. No patients underwent neoadjuvant chemotherapy, while adjuvant treatment was carried out in $42 \%$ of patients.

Median follow-up was 25 months (range 18-27 months). Overall survival outcomes are summarized in Table 3. Iijima et al ${ }^{[46]}$ reported an overall 3-year survival rate of $30 \%$. Kobayashi et al. ${ }^{[47]}$ showed a median survival time following pulmonary resection of 67 months and an overall 5-year survival rate of 59\%, while Shiono et al. ${ }^{[44]}$ reported a value of $28 \%$. By contrast, Yoshida et al ${ }^{[45]}$ followed patients for a median time of 27 months and the overall survival rates at 1, 3 and 4 years were $100 \%, 100 \%$, and $75 \%$, respectively. None of the included studies reported data regarding palliative treatment arms involving chemotherapy alone.

\section{Palliative gastrectomy}

Nine studies providing data on 1115 patients who underwent palliative gastric resection were included [Table 4]. One of these was a randomized controlled trial (REGATTA) ${ }^{[58]}$. The median sample size was 137 patients (range 23-218), and 68\% of patients were males. Except for the randomized controlled trial, inclusion criteria and study structure were very heterogeneous between series and, consequently a comparison of results between them was 


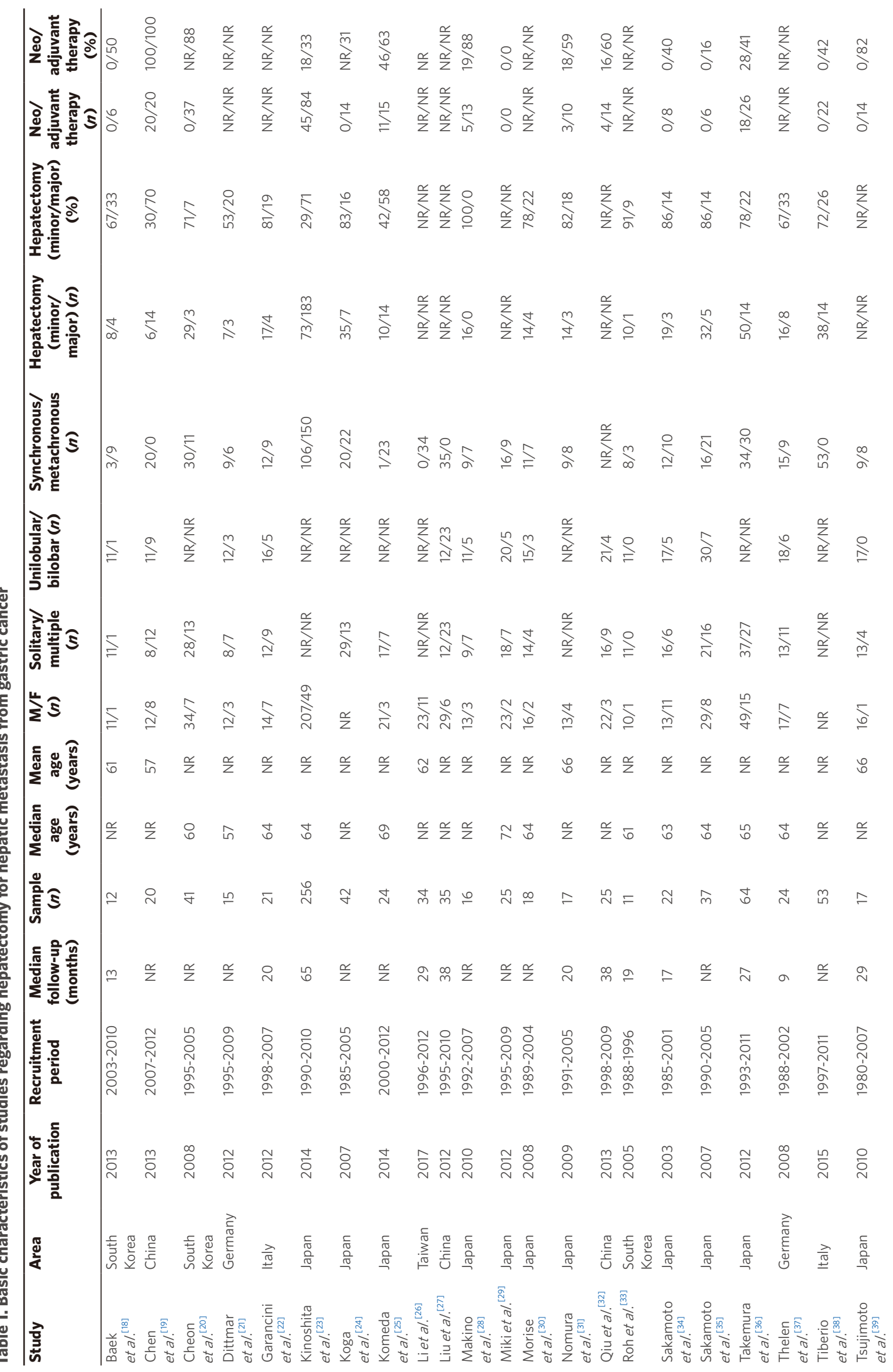




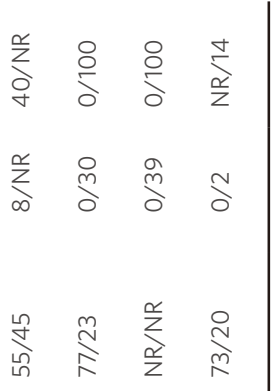

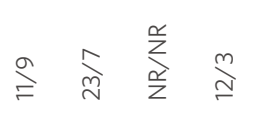

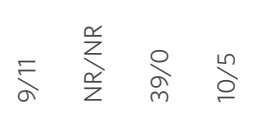

$$
\begin{aligned}
& \stackrel{\infty}{\stackrel{n}{\sim}} \underset{\sim}{\stackrel{n}{v}} \stackrel{\frac{\alpha}{z}}{\frac{v}{z}}
\end{aligned}
$$

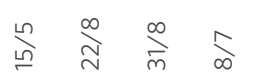

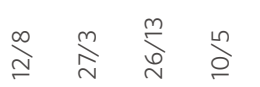

$$
\begin{aligned}
& \text { 兄 品 娄 品 } \\
& \text { ธㅇำ 을 } \\
& \text { ㅇํ } \stackrel{m}{n} \\
& \stackrel{m}{q} \stackrel{\alpha}{z} \quad \frac{\alpha}{z}
\end{aligned}
$$

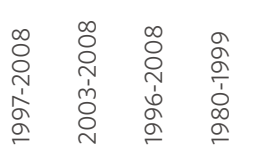

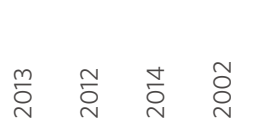

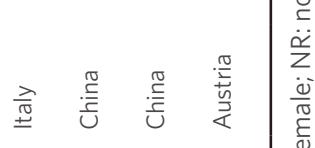

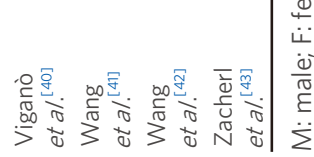

challenging. In addition, in these retrospective studies, the indications for palliative gastrectomy were judged individually by surgeons based on patients' general health, performance status, symptoms, extent of disease, and feasibility of resection.

The minority of palliative resections were total gastrectomies, while $62 \%$ of patients underwent minor resection. Data regarding adjuvant treatment were reported in 7 of the 9 studies, and overall $71 \%$ of patients underwent post-operative chemotherapy; only one study reported data about neoadjuvant treatment ${ }^{[9]}$. Median overall survival was 12 months (range 8-53 months). In 6 of the 8 retrospective studies, a comparison with nonresected patients was carried out, and gastrectomy showed a significant survival advantage in 5 of them; however, these results had limitations related to the retrospective nature and the selection bias for surgery. In fact, in the REGATTA trial, the median overall survival was 16.6 months for patients assigned to chemotherapy alone and 14.3 months for those assigned to gastrectomy plus chemotherapy, in whom significantly higher rates of adverse events were also seen.

\section{DISCUSSION}

The most appropriate treatment in cases of stage IV gastric cancer is still debated. Indications and advantages of a surgical approach to treat advanced gastric neoplasms in comparison to conservative therapy such as chemotherapy have not yet been established. Gastric cancers are mostly of advanced stage at diagnosis. However, location and number of metastases, as well as patient characteristics, influence the benefit of surgical treatment and overall survival outcomes. This systematic review showed that surgery seems to play an important role even in patients with incurable gastric cancer.

In our study, surgical resection of gastric cancer with hepatic metastasis in the absence of peritoneal disease is associated with 1-, 3- and 5-year survival rates of 73\%, 37\%, and $27 \%$ respectively. Median overall survival was 22 months (range 9-52 months). Compared to the results of randomized controlled trials based on chemotherapy, hepatectomy seems to offer in selected patients better survival outcomes ${ }^{[99,60]}$. Liao et al. ${ }^{[61]}$, consistent with previous reviews, described significantly improved overall survival in patients treated with hepatectomy compared to palliative chemotherapy. In light of these studies, the Japanese guidelines reconsidered the role of hepatectomy in the treatment of liver metastasis in gastric cancer, however, which patients may actually benefit from surgical treatment is still controversial. Medical comorbidities of patients undergoing hepatectomy were poorly described in the included studies, as were other confounders like metastasic features, use of neoadjuvant and adjuvant treatment, and surgical techniques. With regard to surgical approach, minor hepatectomy was performed more commonly than major resection (58\% vs. $42 \%$ ). Synchronous, multiple, or bilobar metastases were associated in some studies with poorer prognosis, but were not necessarily considered contraindications for surgery ${ }^{[24,28,35]}$. Chemotherapy was commonly used in the adjuvant and neoadjuvant setting. However, there was a wide variation in timing and regimens between studies. Therefore, from the current literature, the indications for a surgical approach to gastric cancer metastatic to the liver, in particular, the threshold for number of metastases and their location and the administration of chemotherapy in relation to surgery, remain undetermined. 
Table 2. Survival outcomes following hepatectomy for liver metastasis from gastric cancer, with a comparison with nonresected patients (chemotherapy alone)

\begin{tabular}{|c|c|c|c|c|c|c|}
\hline Study & $\begin{array}{c}\text { 1-year survival } \\
\text { (\%) }\end{array}$ & $\begin{array}{c}\text { 3-year survival } \\
\text { (\%) }\end{array}$ & $\begin{array}{c}\text { 5-year survival } \\
\text { (\%) }\end{array}$ & $\begin{array}{l}\text { Median survival } \\
\text { (months) }\end{array}$ & $\begin{array}{c}\text { Nonresected } \\
\text { patients, } \\
\text { median OS } \\
\text { (months) }\end{array}$ & $P$ value \\
\hline Baek et al. ${ }^{[18]}$ & 65 & NR & 39 & 31 & - & - \\
\hline Chen et al. ${ }^{[19]}$ & NR & NR & 15 & 22 & 5.5 & 0.000 \\
\hline Cheon et $a{ }^{[20]}$ & 75 & 32 & 21 & 17 & NR & 0.0001 \\
\hline Dittmar et al. ${ }^{[21]}$ & NR & NR & 27 & 48 & 9 & 0.002 \\
\hline Garancini et al..$^{[22]}$ & 68 & 31 & 19 & 11 & - & - \\
\hline Kinoshita et $a]^{[23]}$ & 77 & 42 & 31 & 31 & - & - \\
\hline Koga et al. ${ }^{[24]}$ & 76 & 48 & 42 & 34 & - & - \\
\hline Komeda et al. ${ }^{[25]}$ & 78 & 40 & 40 & 22 & - & - \\
\hline Li et $a{ }^{[26]}$ & 74 & 37 & 25 & 26 & 3.13 & 0.001 \\
\hline Liu et al. ${ }^{[27]}$ & 58 & 22 & NR & 15 & - & - \\
\hline Makino et al. ${ }^{[28]}$ & 88 & 56 & 42 & 38 & 15 & 0.001 \\
\hline Miki et al. ${ }^{[29]}$ & 74 & 43 & 37 & 33 & NR & 0.04 \\
\hline Morise et $a l_{.}^{[30]}$ & 56 & 27 & 27 & 13 & - & - \\
\hline Nomura et al. ${ }^{[31]}$ & NR & NR & 31 & 21 & - & - \\
\hline Qiu et al. ${ }^{[32]}$ & 96 & 70 & 29 & 38 & - & - \\
\hline Roh et al. ${ }^{[33]}$ & 73 & NR & 27 & 19 & - & - \\
\hline Sakamoto et al. ${ }^{[34]}$ & 73 & 38 & 38 & 21 & - & - \\
\hline Sakamoto et al. ${ }^{[35]}$ & NR & NR & 11 & 31 & - & - \\
\hline Takemura et al. ${ }^{[36]}$ & 84 & 50 & 37 & 34 & - & - \\
\hline Thelen et al. ${ }^{[37]}$ & 38 & 16 & 10 & 9 & - & - \\
\hline Tiberio et $a l .{ }^{[38]}$ & 50 & 14 & 9 & 13 & - & - \\
\hline Tsujimoto et al. ${ }^{[39]}$ & NR & NR & 32 & 34 & - & - \\
\hline Viganò et al. ${ }^{[40]}$ & 95 & 63 & 33 & 52 & - & - \\
\hline Wang et al. ${ }^{[41]}$ & 43 & 17 & 17 & 11 & - & - \\
\hline Wang et al. ${ }^{[42]}$ & 56 & 18 & 10 & 14 & NR & $\begin{array}{l}\text { NR } \\
\text { (but referred } \\
<0.05 \text { ) }\end{array}$ \\
\hline Zacherl et al. ${ }^{[43]}$ & 36 & 29 & 14 & 9 & - & - \\
\hline
\end{tabular}

NR: not reported; OS: overall survival

Resection of lung metastases from gastric cancer has rarely been reported, and only small amounts of heterogeneous data are available regarding short- and long-term outcomes. The majority of articles present in the literature are case reports or small series. Only four studies were included in our evaluation. They reported favorable results in the surgical group; however, the series were small, and comparison between studies was difficult because of the heterogeneity of inclusion criteria for each study. Overall 3-year survival rates ranged from $30 \%$ to $100 \%$. The frequent occurrence of extrapulmonary metastases before pulmonary metastasectomy restricts surgical treatment to highly selected patient ${ }^{[56]}$. In this setting, lung metastasectomy seems not to have a determined role in the standard management of these patients.

In the 1115 patients included in this review who underwent palliative gastrectomy, median overall postresection survival was 12 months. The rationale for non-curative gastrectomy was the reduction of tumor burden and/or the palliation of symptoms, such as obstruction, perforation, bleeding or ascites. In 6 of the 8 retrospective studies included in this review, overall survival of resected patients was significantly better than the nonresected group. However, all studies highlighted as a limitation, the possible relationship between these positive results and the selection bias of patients. A previous meta-analysis was consistent with these results ${ }^{[62]}$. Moreover, they analyzed survival rates of patients that received palliative gastrectomy with or without chemotherapy, and it was shown that surgery combined with chemotherapy offered a survival benefit ${ }^{[62]}$. By contrast, the results of the REGATTA trial showed no survival benefit of additional gastrectomy over chemotherapy alone, not justifying gastric resection in patients with metastatic gastric cancer ${ }^{[58]}$. In light of this randomized controlled trial, chemotherapy alone remains the standard of care for 


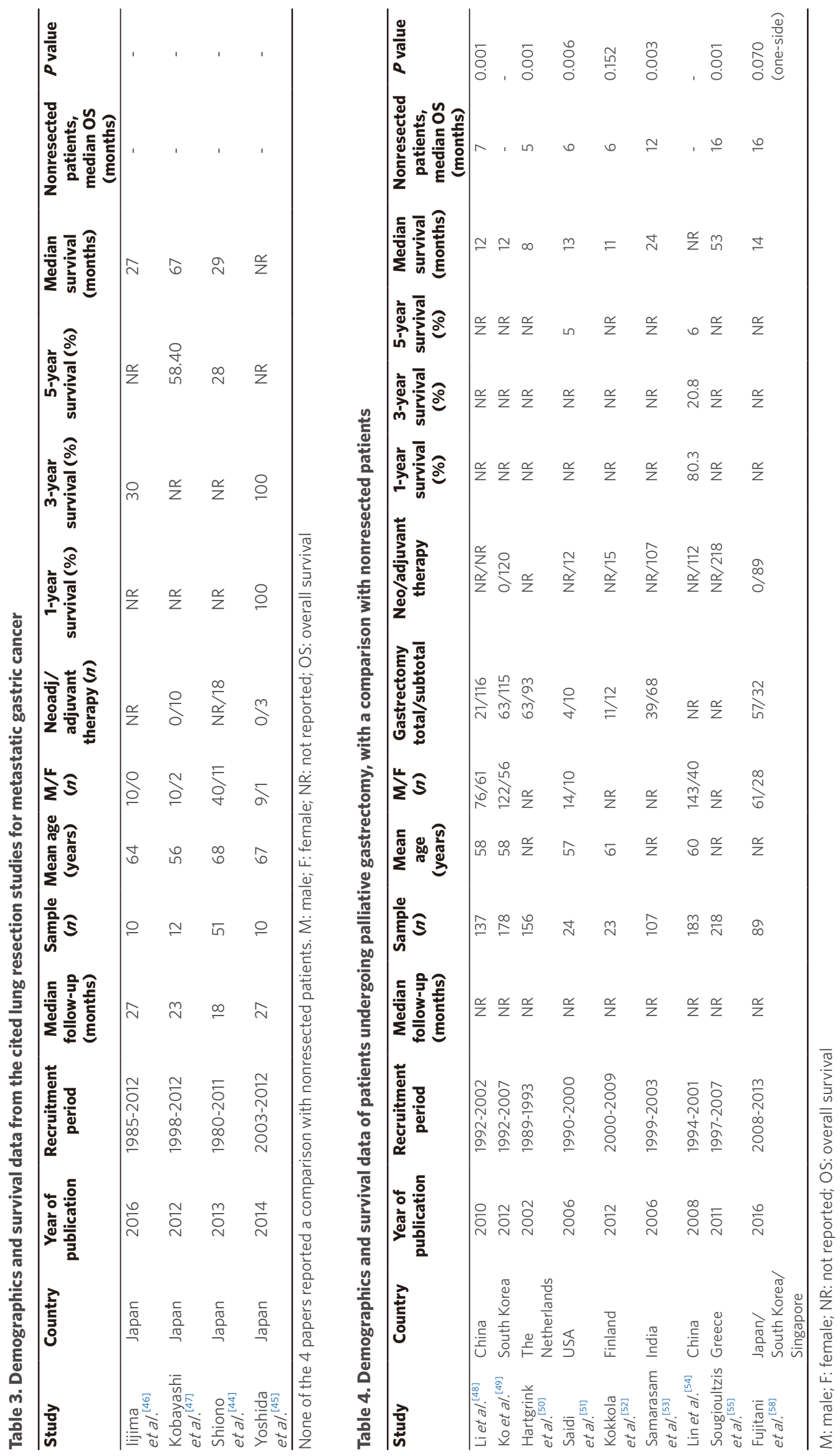


these patients, even though the chemotherapy regimen used in the REGATTA trial was based on S-1, which shows reduced tolerability in Western patients ${ }^{[63]}$.

In summary, from the present literature, a surgical approach for stage IV gastric cancer shows uncertain survival benefits and is not justified in all patients. Further randomized controlled trials are necessary to clarify the actual impact of surgery in these patients. Probably, surgery may play an important role in highly selected patients. Criteria to select patients who can benefit more from surgical treatment have not yet been identified, and this needs further investigation.

\section{DECLARATIONS}

\section{Acknowledgments}

We would like to thank Dr. Robin Vasan from Department of Surgery, Massachusetts General Hospital, Harvard Medical School for language editing.

\section{Authors' contributions}

Concept, design, definition of intellectual content: Pergolini I, Ciano P, Guercioni G, Catarci M

Literature search, data acquisition, data analysis, statistical analysis: Pergolini I, Ciano P

Manuscript preparation: Pergolini I, Catarci M

Manuscript editing, manuscript review: Pergolini I, Ciano P, Guercioni G, Catarci M

\section{Availability of data and materials}

Data are searched and available from PubMed, MEDLINE, Embase.

\section{Financial support and sponsorship}

None.

\section{Conflicts of interest}

All authors declared that there are no conflicts of interest.

\section{Ethical approval and consent to participate}

Not applicable.

\section{Consent for publication}

Not applicable.

\section{Copyright}

(c) The Author(s) 2018.

\section{REFERENCES}

1. Blot WJ, Devesa SS, Kneller RW FJJ. Rising incidence of adenocarcinoma of the esophagus and gastric cardia. JAMA 1991;265:1287-9.

2. Siegel R, Miller K, Jemal A. Cancer statistics, 2017. CA Cancer J Clin 2017;67:7-30.

3. National Cancer Institute - Surveillance, Epidemiology, and End Results Program. SEER*Stat Databases: November 2015 Submission. Available from: https://seer.cancer.gov/data/seerstat/nov2015/ [Last accessed on 27 Feb 2018].

4. Shin A, Kim J, Park S. Gastric cancer epidemiology in Korea. J Gastric Cancer 2011;11:135-40.

5. Kemp CD, Kitano M, Kerkar S, Ripley RT, Marquardt JU, Schrump DS, Avital I. Pulmonary resection for metastatic gastric cancer. J Thorac Oncol 2010;5:1796-805.

6. Spolverato G, Ejaz A, Kim Y, Squires MH, Poultsides GA, Fields RC, Schmidt C, Weber SM, Votanopoulos K, Maithel SK, Pawlik TM. Rates and patterns of recurrence after curative intent resection for gastric cancer: a United States multi-institutional analysis. J Am Coll Surg 2014;219:664-75.

7. Deng J, Liang H, Wang D, Sun D, Pan Y, Liu Y. Investigation of the recurrence patterns of gastric cancer following a curative resection. 
Surg Today 2011;41:210-5.

8. Nio Y, Koike M, Omori H, Hashimoto K, Itakura M, Yano S, Higami T, Maruyama R. A randomized consent design trial of neoadjuvant chemotherapy with tegafur plus uracil (UFT) for gastric cancer - a single institute study. Anticancer Res 2004;24:1879-87.

9. Kodera Y, Sano T. Japanese gastric cancer treatment guidelines 2014 (ver. 4). Gastric Cancer 2017;20:1-19.

10. Ajani JA, D’Amico TA, Almhanna K, Bentrem DJ, Chao J, Das P, Denlinger CS, Fanta P, Farjah F, Fuchs CS, Gerdes H, Gibson M, Glasgow RE, Hayman JA, Hochwald S, Hofstetter WL, Ilson DH, Jaroszewski D, Johung KL, Keswani RN, Kleinberg LR, Korn WM, Leong S, Linn C, Lockhart AC, Ly QP, Mulcahy MF, Orringer MB, Perry KA, Poultsides GA, Scott WJ, Strong VE, Washington MK, Weksler B, Willett CG, Wright CD, Zelman D, McMillian N, Sundar H. Gastric Cancer, Version 3.2016, NCCN Clinical Practice Guidelines in Oncology. J Natl Compr Canc Netw 2016;14:1286-312.

11. Kodera Y, Fujitani K, Fukushima N, Ito S, Muro K, Ohashi N, Yoshikawa T, Kobayashi D, Tanaka C, Fujiwara M. Surgical resection of hepatic metastasis from gastric cancer: a review and new recommendation in the Japanese gastric cancer treatment guidelines. Gastric Cancer 2014;17:206-12.

12. AJCC. Cancer Staging Manual, 7th edition. New York: Springer-Verlag; 2010.

13. AJCC. Cancer Staging Manual, 8th edition. New York: Springer-Verlag; 2016.

14. AJCC. Cancer Staging Manual, 6th edition. New York: Springer-Verlag; 2003.

15. Sano T, Kodera Y. Japanese classification of gastric carcinoma: 3rd English edition. Gastric Cancer 2011;14:101-12.

16. Bosman FT, Carneiro F, Hruban RH, Theise ND. WHO classification of tumours of the digestive system. Lyon: IARC Press; 2010.

17. Hu B, El Hajj N, Sittler S, Lammert N, Barnes R, Meloni-Ehrig A. Gastric cancer: classification, histology and application of molecular pathology. J Gastrointest Oncol 2012;3:251-61.

18. Baek HU, Kim SB, Cho EH, Jin SH, Yu HJ, Lee JI, Bang HY, Lim CS. Hepatic resection for hepatic metastases from gastric adenocarcinoma. J Gastric Cancer 2013;13:86-92.

19. Chen L, Song MQ, Lin HZ, Hao LH, Jiang XJ, Li ZY, Chen YX. Chemotherapy and resection for gastric cancer with synchronous liver metastases. World J Gastroenterol 2013;19:2097-103.

20. Cheon SH, Rha SY, Jeung HC, Im CK, Kim SH, Kim HR, Ahn JB, Roh JK, Noh SH, Chung HC. Survival benefit of combined curative resection of the stomach (D2 resection) and liver in gastric cancer patients with liver metastases. Ann Oncol 2008;19:1146-53.

21. Dittmar Y, Altendorf-Hofmann A, Rauchfuss F, Götz M, Scheuerlein H, Jandt K, Settmacher U. Resection of liver metastases is beneficial in patients with gastric cancer: report on 15 cases and review of literature. Gastric Cancer 2012;15:131-6.

22. Garancini M, Uggeri F, Degrate L, Nespoli L, Gianotti L, Nespoli A, Uggeri F, Romano F. Surgical treatment of liver metastases of gastric cancer: is local treatment in a systemic disease worthwhile? HPB 2012;14:209-15.

23. Kinoshita T, Kinoshita T, Saiura A, Esaki M, Sakamoto H, Yamanaka T. Multicentre analysis of long-term outcome after surgical resection for gastric cancer liver metastases. Br J Surg 2015;102:102-7.

24. Koga R, Yamamoto J, Ohyama S, Saiura A, Seki M, Seto Y, Yamaguchi T. Liver resection for metastatic gastric cancer: Experience with 42 patients including eight long-term survivors. Jpn J Clin Oncol 2007;37:836-42.

25. Komeda K, Hayashi M, Kubo S, Nagano H, Nakai T, Kaibori M, Wada H, Takemura S, Kinoshita M, Koga C, Matsumoto M, Sakaguchi T, Inoue Y, Hirokawa F, Kwon AH, Uchiyama K. High survival in patients operated for small isolated liver metastases from gastric cancer: a multi-institutional study. World J Surg 2014;38:2692-7.

26. Li S, Lee C, Hung C, Wu J, Chen J. Surgical resection of metachronous hepatic metastases from gastric cancer improves long-term survival: a population-based study. PLoS One 2017;12:1-10.

27. Liu J, Li JH, Zhai RJ, Wei B, Shao MZ, Chen L. Predictive factors improving survival after gastric and hepatic surgical treatment in gastric cancer patients with synchronous liver metastases. Chin Med J 2012;125:165-71.

28. Makino H, Kunisaki C, Izumisawa Y, Tokuhisa M, Oshima T, Nagano Y, Fujii S, Kimura J, Takagawa R, Kosaka T, Ono HA, Akiyama H, Tanaka K, Endo I. Indication for hepatic resection in the treatment of liver metastasis from gastric cancer. Anticancer Res 2010;30:2367-76.

29. Miki Y, Fujitani K, Hirao M, Kurokawa Y, Mano M, Tsujie M, Miyamoto A, Nakamori S, Tsujinaka T. Significance of surgical treatment of liver metastases from gastric cancer. Anticancer Res 2012;32:665-70.

30. Morise Z, Sugioka A, Hoshimoto S, Kato T, Ikeda M, Uyama I, Horiguchi A, Miyakawa S. The role of hepatectomy for patients with liver metastases of gastric cancer. Hepatogastroenterology 2008;55:1238-4.

31. Nomura T, Kamio Y, Takasu N, Moriya T, Takeshita A, Mizutani M, Hachiya O, Hirai I, Kimura W. Intrahepatic micrometastases around liver metastases from gastric cancer. J Hepatobiliary Pancreat Surg 2009;16:493-501.

32. Qiu JL, Deng MG, Li W, Zou RH, Li BK, Zheng Y, Lao XM, Zhou K, Yuan YF. Hepatic resection for synchronous hepatic metastasis from gastric cancer. Eur J Surg Oncol 2013;39:694-700.

33. Roh H, Suh K, Lee H, Yang H, Choe K, Lee K. Outcome of hepatic resection for metastatic gastric cancer. Am Surg 2005;71:95-9.

34. Sakamoto Y, Ohyama S, Yamamoto J, Yamada K, Seki M, Ohta KI, Kokudo N, Yamaguchi T, Muto T, Makuuchi M. Surgical resection of liver metastases of gastric cancer: an analysis of a 17-year experience with 22 patients. Surgery 2003;133:507-11.

35. Sakamoto Y, Sano T, Shimada K, Esaki M, Saka M, Fukagawa T, Katai H, Kosuge T, Sasako M. Favorable indications for hepatectomy in patients with liver metastasis from gastric cancer. J Surg Oncol 2007;95:534-9.

36. Takemura N, Saiura A, Koga R, Arita J, Yoshioka R, Ono Y, Hiki N, Sano T, Yamamoto J, Kokudo N, Yamaguchi T. Longterm outcomes after surgical resection for gastric cancer liver metastasis: an analysis of 64 macroscopically complete resections. Langenbecks Arch Surg 2012;397:951-7.

37. Thelen A, Jonas S, Benckert C, Lopez-Hänninen E, Neumann U, Rudolph B, Schumacher G, Neuhaus P. Liver resection for metastatic gastric cancer. Eur J Surg Oncol 2008;34:1328-34.

38. Tiberio GAM, Baiocchi GL, Morgagni P, Marrelli D, Marchet A, Cipollari C, Graziosi L, Ministrini S, Vittimberga G, Donini A, Nitti D, 
Roviello F, Coniglio A, de Manzoni G. Gastric cancer and synchronous hepatic metastases: is it possible to recognize candidates to R0 resection? Ann Surg Oncol 2015;22:589-96.

39. Tsujimoto H, Ichikura T, Ono S, Sugasawa H, Hiraki S, Sakamoto N, Yaguchi Y, Hatsuse K, Yamamoto J, Hase K. Outcomes for patients following hepatic resection of metastatic tumors from gastric cancer. Hepatol Int 2010;4:406-13.

40. Viganò L, Vellone M, Ferrero A, Giuliante F, Nuzzo G, Capussotti L. Liver resection for gastric cancer metastases. Hepatogastroenterology 2013;60:557-62.

41. Wang YN, Shen KT, Ling JQ, Gao XD, Hou YY, Wang XF, Qin J, Sun YH, Qin XY. Prognostic analysis of combined curative resection of the stomach and liver lesions in 30 gastric cancer patients with synchronous liver metastases. BMC Surg 2012;12:20.

42. Wang W, Liang H, Zhang H, Wang X, Xue Q, Zhang R. Prognostic significance of radical surgical treatment for gastric cancer patients with synchronous liver metastases. Med Oncol 2014;31:1-8.

43. Zacherl J, Zacherl M, Scheuba C, Steininger R, Wenzl E, Mühlbacher F, Jakesz R, Längle F. Analysis of hepatic resection of metastasis originating from gastric adenocarcinoma. J Gastrointest Surg 2002;6:682-9.

44. Shiono S, Sato T, Horio H, Chida M, Matsuguma H, Ozeki Y, Nakajima J, Okumura S. Outcomes and prognostic factors of survival after pulmonary resection for metastatic gastric cancer. Eur J Cardiothorac Surg 2013;43:e13-6.

45. Yoshida Y, Imakiire T, Yoneda S, Obuchi T, Inada K, Iwasaki A. Ten cases of resected solitary pulmonary metastases arising from gastric cancer. Asian Cardiovasc Thorac Ann 2013;22:578-82.

46. Iijima Y, Akiyama H, Atari M, Fukuhara M, Nakajima Y, Kinosita H, Uramoto H. Pulmonary resection for metastatic gastric cancer. Ann Thorac Cardiovasc Surg 2016;22:230-6.

47. Kobayashi Y, Fukui T, Ito S, Shitara K, Ito S, Hatooka S, Mitsudomi T. Pulmonary metastasectomy for gastric cancer: a 13-year singleinstitution experience. Surg Today 2013;43:1382-9.

48. Li C, Yan M, Chen J, Xiang M, Zhu ZG, Yin HR, Lin YZ. Survival benefit of non-curative gastrectomy for gastric cancer patients with synchronous distant metastasis. J Gastrointest Surg 2010;14:282-8.

49. Ko KJ, Shim JH, Yoo HM, Il SO, Jeon HM, Park CH, Jeon DJ, Song KY. The clinical value of non-curative resection followed by chemotherapy for incurable gastric cancer. World J Surg 2012;36:1800-5.

50. Hartgrink HH, Putter H, Klein Kranenbarg E, Bonenkamp JJ, van de Velde CJH. Value of palliative resection in gastric cancer. Br J Surg 2002;89:1438-43.

51. Saidi RF, ReMine SG, Dudrick PS, Hanna NN. Is there a role for palliative gastrectomy in patients with stage IV gastric cancer? World J Surg 2006;30:21-7.

52. Kokkola A, Louhimo J, Puolakkainen P. Does non-curative gastrectomy improve survival in patients with metastatic gastric cancer? J Surg Oncol 2012;106:193-6.

53. Samarasam I, Chandran BS, Sitaram V, Perakath B, Nair A, Mathew G. Palliative gastrectomy in advanced gastric cancer: is it worthwhile? ANZ J Surg 2006;76:60-3.

54. Lin SZ, Tong HF, You T, Yu YJ, Wu WJ, Chen C, Zhang W, Ye B, Li CM, Zhen ZQ, Xu JR, Zhou JL. Palliative gastrectomy and chemotherapy for stage IV gastric cancer. J Cancer Res Clin Oncol 2008;134:187-92.

55. Sougioultzis S, Syrios J, Xynos ID, Bovaretos N, Kosmas C, Sarantonis J, Dokou A, Tzivras D, Zografos G, Felekouras E, Papalambros E, Tsavaris N. Palliative gastrectomy and other factors affecting overall survival in stage IV gastric adenocarcinoma patients receiving chemotherapy: a retrospective analysis. Eur J Surg Oncol 2011;37:312-8.

56. Funakoshi T, Yasui H, Boku N, Fukutomi A, Yamazaki K, Machida N, Todaka A, Tsushima T, Yokota T, Onozawa Y, Kenmotsu H, Endo M. Clinicopathological features and outcomes of gastric cancer patients with pulmonary lymphangitis carcinomatosa. Jpn J Clin Oncol 2014;44:792-8.

57. Thomford NR, Woolner LB, Clagett OT. The surgical treatment of metastatic tumors in the lungs. J Thorac Cardiovasc Surg 1965;49:357-63.

58. Fujitani K, Yang HK, Mizusawa J, Kim YW, Terashima M, Han SU, Iwasaki Y, Hyung WJ, Takagane A, Park DJ, Yoshikawa T, Hahn S, Nakamura K, Park CH, Kurokawa Y, Bang YJ, Park BJ, Sasako M, Tsujinaka T16; REGATTA study investigators. Gastrectomy plus chemotherapy versus chemotherapy alone for advanced gastric cancer with a single non-curable factor (REGATTA): a phase 3, randomised controlled trial. Lancet Oncol 2016;17:309-18.

59. Waddell T, Chau I, Cunningham D, Gonzalez D, Frances A, Okines C, Wotherspoon A, Saff C, Middleton G, Wadsley J, Ferry D, Mansoor W, Crosby T, Coxon F, Smith D, Waters J, Iveson T, Falk S, Slater S, Peckitt C, Barbachano Y. Epirubicin, oxaliplatin, and capecitabine with or without panitumumab for patients with previously untreated advanced oesophagogastric cancer (REAL3): a randomised, open-label phase 3 trial. Lancet Oncol 2013;14:481-9.

60. Bang YJ, Van Cutsem E, Feyereislova A, Chung HC, Shen L, Sawaki A, Lordick F, Ohtsu A, Omuro Y, Satoh T, Aprile G, Kulikov E, Hill J, Lehle M, Rüschoff J, Kang YK; ToGA Trial Investigators. Trastuzumab in combination with chemotherapy versus chemotherapy alone for treatment of HER2-positive advanced gastric or gastro-oesophageal junction cancer (ToGA): a phase 3, open-label, randomised controlled trial. Lancet 2010;376:687-97.

61. Liao YY, Peng NF, Long D, Yu PC, Zhang S, Zhong JH, Li LQ. Hepatectomy for liver metastases from gastric cancer: a systematic review. BMC Surg 2017;17:14.

62. Sun J, Song Y, Wang Z, Chen X, Gao P, Xu Y, Zhou B, Xu H. Clinical significance of palliative gastrectomy on the survival of patients with incurable advanced gastric cancer: a systematic review and meta-analysis. BMC Cancer 2013;13:577.

63. Krasniqi E, Pellicori S, Formica V. Emerging role of S-1 in gastric cancer. Indian J Med Paediatr Oncol 2015;36:219-28. 